\title{
Design Considerations for Implementing an Optimal Battery Management System of a Wireless Sensor Node
}

\author{
J. Ashok ${ }^{1 *}$ and P. Thirumoorthy ${ }^{2}$ \\ 'PRIST University, Thanjavur, Tamil Nadu, India; p.rajasekar28@yahoo.com \\ 2Department of Electronics, Government College of Arts and Science, Dharmapuri, Tamil Nadu, India
}

\begin{abstract}
Nowadays, researchers' preferably giving more attention to the power consumption of a sensor node as it is the main criteria in all Wireless Sensor Networks (WSNs). Wireless Sensor Nodes of a network have some major constraints due to their limited energy, storage capacity, computing power and frequent battery replacement factor, when they meant to collect the information from an unattended location using various sensors. Hence the proposed research implements a novel power management system by introducing pack of two solar powered batteries and an automatic battery switching system with LabVIEW based real time data acquisition. The proposed approach avoids the frequent replacement of batteries in the sensor node about $90 \%$. Hill stations, barren region, and unattended location may include the implemented WSN.
\end{abstract}

Keywords: Battery Switching System, DAQ LabVIEW, Wireless Sensor Networks

\section{Introduction}

The entry of Wireless Sensor Networks (WSN) has made a tremendous development in the communication field. Recently, WSN researchers pay attention mainly to the power consumption as it is the main criteria in all WSNs. Normally, the power consumption includes the sensors placed in the nodes, Microcontrollers, wireless transceivers etc ${ }^{1}$. Typically, the sensor node power consumption is calculated by monitoring the battery level of the corresponding node by some special sensors. Those sensors will find out the power status and deliver the status through wireless transceiver. But if there are power shortages, the corresponding node will become a sleep node and data transmission is stopped.

Figure 1 shows a typical wireless sensor node. The wireless sensor node consists of microcontroller unit, sensor array, wireless transceivers and power supply (Battery).

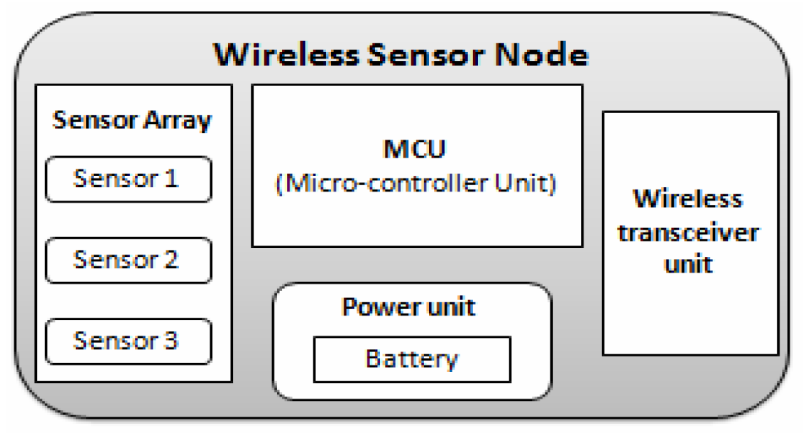

Figure 1. Typical wireless sensor node.

With the availability of basic needful components, a WSN performs the sensing the sensors signal, processing of signals, communication, and data collection properties. Here, the main challenging criteria are powering the wireless sensor node. Various energy supply systems are introduced by the WSN workers. They include thin film batteries, rechargeable batteries ${ }^{2}$. 
Some of the Energy Reservoirs used by the typical sensor nodes are Macro-scale Batteries, Micro-scale Batteries, Micro-fuel Cells, Ultra capacitors and radioactive power sources. Some of the Micro-scale Batteries are Lithium, Alkaline and Zinc air and its energy levels are $2880\left(\mathrm{~J} / \mathrm{cm}^{3}\right), 1200\left(\mathrm{~J} / \mathrm{cm}^{3}\right), 3780\left(\mathrm{~J} / \mathrm{cm}^{3}\right)$ respectively ${ }^{3}$. Now days there are wireless sensor nodes with energy harvesting techniques with rechargeable batteries.

The power supply unit for the sensor node should be capable of offering the total energy required during the lifetime. Figure 2 shows a general block diagram of the power supply unit of a wireless sensor node. The solar cell, power management stage, thin film batteries and the microcontroller unit are the main parts which are combined to generate and deliver the energy needed by the sensor node.

The harvested power $\left(P_{\mathrm{h}}\right)$ should be larger than that power required by the node $\left(P_{\mathrm{r}}\right)$, on average while generating from the energy from the solar source. The sensory elements convert solar light energy into electrical energy, with a given accuracy. For any subjective time period $T$ in which $P_{\mathrm{h}}>P_{\mathrm{r}}$. Table 1 shows the typical energy consumption factors of normal and solar based wireless sensor nodes.

$$
E_{\text {stored }}>\max \left\{\int T\left(P_{\mathrm{h}}-P_{\mathrm{r}}\right) d t\right\} \text {. }
$$

Table 2 shows the comparison between the energy generation factors between primary batteries versus solar energy ${ }^{4}$. In this table the energy generation is compared with the solar indoor, solar outdoor and with the primary batteries. As table describes the solar energy with efficient power managements tools provide large amount of energy production than other battery power supply.

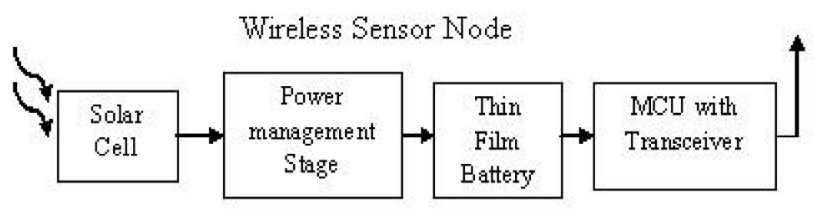

Figure 2. Power supply module of sensor node.

Table 1. Power and daily energy consumption of node

\begin{tabular}{lcc}
\hline Mode of operation & $\mathrm{P}_{\text {average }}(\mathrm{mW})$ & $\mathrm{E}_{\text {day }}(\mathrm{mWh})$ \\
\hline Continuous & 108 & 2592 \\
Periodic $(\mathrm{D}=0.1 \%)$ & 0.111 & 2.664 \\
\hline
\end{tabular}

Table 2. Primary batteries versus solar cells

\begin{tabular}{lccc}
\hline & & \multicolumn{2}{c}{ Power supply size } \\
\cline { 3 - 4 } Energy Source & Power Density & $\begin{array}{c}\text { Continuous } \\
\text { Operation }\end{array}$ & $\begin{array}{c}\text { Periodical } \\
\text { Operation }\end{array}$ \\
\hline Solar Outdoors & $1.42 \mathrm{~mW} / \mathrm{cm}^{2}$ & $76 \mathrm{~cm}^{2}$ & $0.078 \mathrm{~cm}^{2}$ \\
Solar Indoors & $0.017 \mathrm{~mW} / \mathrm{cm}^{2}$ & $6480 \mathrm{~cm}^{2}$ & $6.7 \mathrm{~cm}^{2}$ \\
Battery & $0.018 \mathrm{~mW} / \mathrm{cm}^{3}$ & $5913 \mathrm{~cm}^{3}$ & $6.1 \mathrm{~cm}^{3}$ \\
\hline
\end{tabular}

Hence the research clearly focuses power production with solar energy and power management system using pack of two rechargeable batteries.

\section{Motivation of the Research}

Powering of wireless sensor nodes without a permanent/ long life battery is a common problem which is often solved by involving alternative energy sources. One of the most generally used sources is solar power. However, the general solar powered wireless sensor node comes with only one rechargeable battery with charging circuit. It doesn't produce an optimized power supply to the sensor node in the bad weather conditions. Hence the motivation of the research is focusing on implementing a power optimized, fully controlled, solar powered, charging and discharging system to the sensor node.

The modern wireless sensor networks deals with power consumption by the sensor node, communication defects, mobility of nodes, size of the sensor node and cost of the sensor node. One of the main considerations of the WSN workers is the power supply system to the sensor node.

Hence, this research implements a power optimized, fully controlled, and solar powered charging, discharging unit with the pack of two rechargeable batteries by automatic battery switching technique Figure 3. Secondly it implements a LabVIEW based data acquisition ${ }^{5}$ of Wireless Sensor Network (WSN).

\section{Automatic Battery Switching System (ABSS)}

Figure 4 shows a power optimized fully controlled, and solar powered charging and discharging system with the pack of two rechargeable batteries. It involves the switches S1, S2, S3, S4 and S5 to control the Automatic Battery Switching System (ABSS). The switch status for charging 


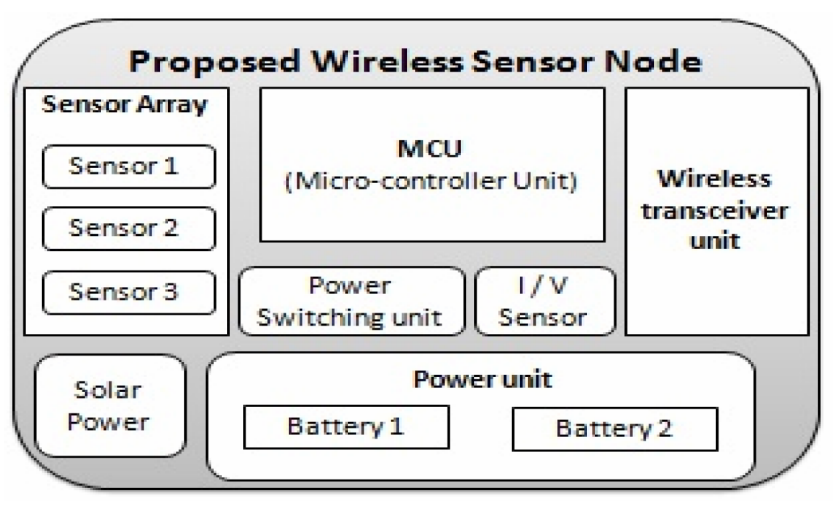

Figure 3. Proposed wireless sensor node architecture.

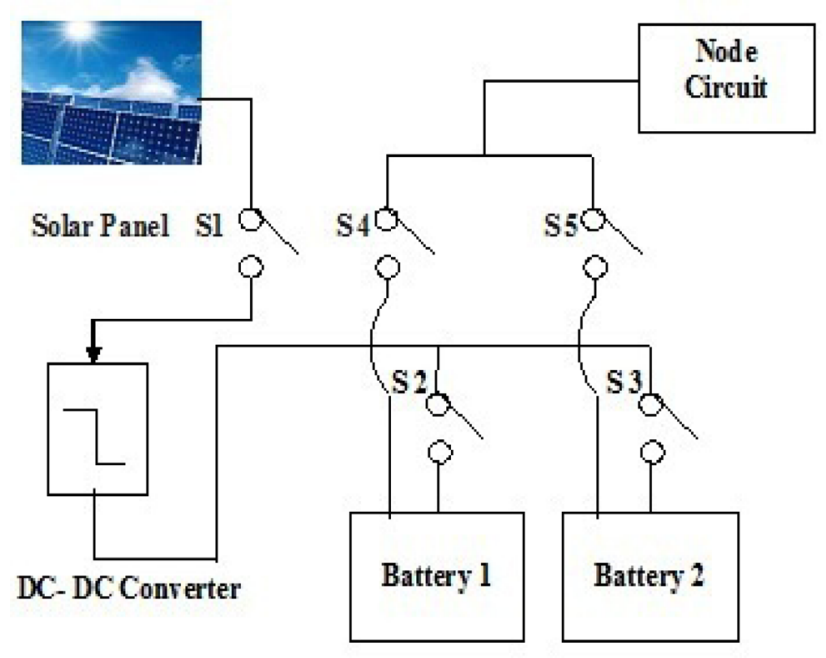

Figure 4. Automatic Battery Switching System.

and discharging the battery 1 and battery 2 respectively is listed in Table 3.

The design proposed in this research involves two separate rechargeable battery units working alternately. Thus, when the first battery gets the power from the solar system, the second battery delivers sensor node by all the power required by it. But, in a general conventional wireless sensor network the power source is used to recharge only a single battery as in Figure 5.

The BCDS (Battery Charging and Discharging System) is key element which connects the charging and discharging paths between the batteries and the wireless sensor node. This BCDS system is given two power sensors for the batteries to check the availability of the power in them. According to the power status data sets the BCDS will take care of two major works. In its first work it will route the power from the solar system to the battery which is being to be charged and in its second work,
Table 3. Battery Charge Discharge Mode

\begin{tabular}{|c|c|c|c|c|c|c|}
\hline \multicolumn{2}{|c|}{$\begin{array}{l}\text { Charge/Discharge } \\
\text { Condition }\end{array}$} & \multicolumn{5}{|c|}{ Switch Conditions } \\
\hline Battery 1 & Battery 2 & S1 & S2 & S3 & S4 & S5 \\
\hline Charge & Discharge & $\mathrm{ON}$ & $\mathrm{ON}$ & OFF & OFF & $\mathrm{ON}$ \\
\hline Discharge & Charge & ON & OFF & ON & $\mathrm{ON}$ & OFF \\
\hline
\end{tabular}

Figure 5. Model of a solar powered sensor node.

it routes the battery which has take care of powering the system to the sensor node (Figure 6).

In order to do this works efficiently the BCDS unit follows the set of conditions which are used to control the paths for the charging and discharging process as it in Table 3. In first condition, BCDS is charging battery 1 and discharging battery 2 . In second condition, BCDS is charging battery 2 and discharging battery 1 . BCDS is set to supply the sensor node directly from the solar power if both the batteries are fully discharged.

This system consists of a DC-DC synchronousrectified converter and the charger unit controlled by a PWM signal which is applied to one of its terminals and supplies each battery according to a programmed algorithm in the micro controller. Between the solar panel and the Battery charger system there are a voltage conditioning capacitor and I/V sensor from Autopilot with $0-3.3 \mathrm{~V}$ output $^{6}$. The capacitor prevents voltage at the charger input pin from falling below the charge voltage of the battery cells when solar power is not capable of providing appropriate voltage level. The role of $\mathrm{I} / \mathrm{V}$ sensor is detecting the current and voltage levels that solar panels provide to the charger device.

\section{Practical Considerations of WSN Data Acquisition}

Wireless data acquisition system overcomes the challenges related with configuring and monitoring data 


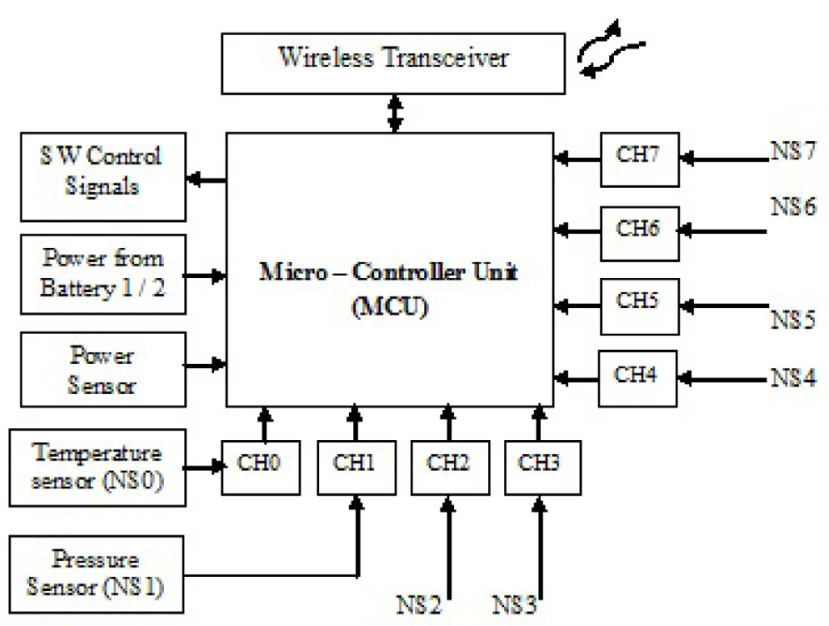

Figure 6. Battery charging and discharging system.

acquisition, storing data for future processing, efficiently analyzing the collected data and showing data to the remote user in a helpful way ${ }^{7}$. For this the collected information should follow a data format as it is shown in Figure 7 in order to clear data acquisition process. Proposed Data Acquisition involves: Acquiring signals from real-world sensors, digitizing the sensor signals, Analyzing, displaying and saving the data and showing the battery conditions.

\section{LabVIEW Data Acquisition Results}

When the simulation is over, the result files contain data over time which can be directly analyzed to present the results below result windows. Results are grouped into Sensors data, battery 1 and battery 2 data, charging discharging details of both battery date time and all other necessary data required in the WSN System ${ }^{8}$ as it is in the Figures 8, 9, 10 and 11 respectively. For each device the simulator provides the equipment value, equivalent graph the voltage, and the power. Thus, harvested energy, total consumed energy, battery changing time, battery conditions and power peaks are easily monitored and stored in the database.

\section{Conclusion of the Proposed System}

Our work is focused on introducing the 3rd generation power supply management and control system with the

\begin{tabular}{|l|l|l|l|l|}
\hline NODE ID & SENSOR 1 & SENSOR 2 & SENSOR 3 & SENSOR 4 \\
\hline
\end{tabular}

Figure 7. Data frame structure used in sensor node.

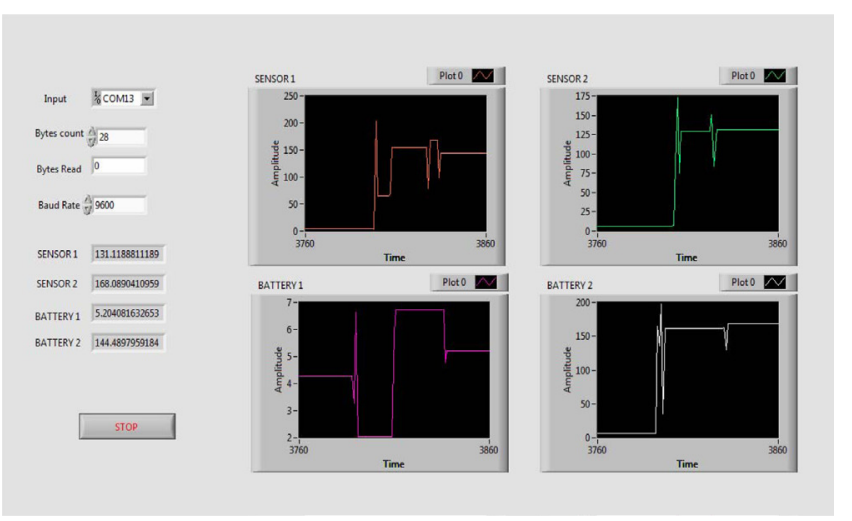

Figure 8. LabVIEW result window of data acquisition.

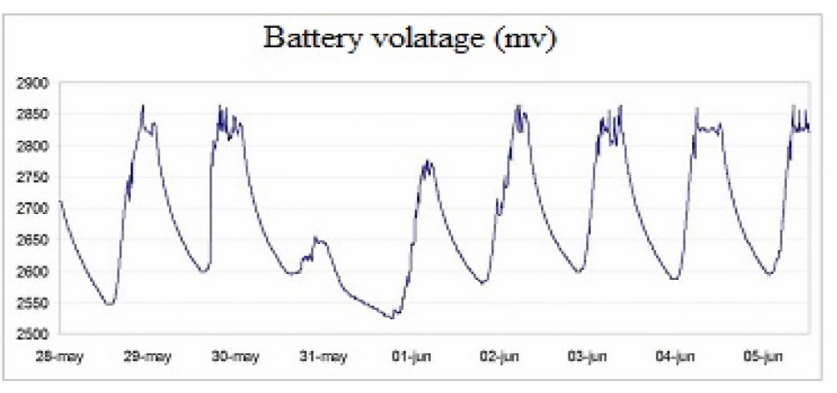

Figure 9. Battery voltage of sensor node.

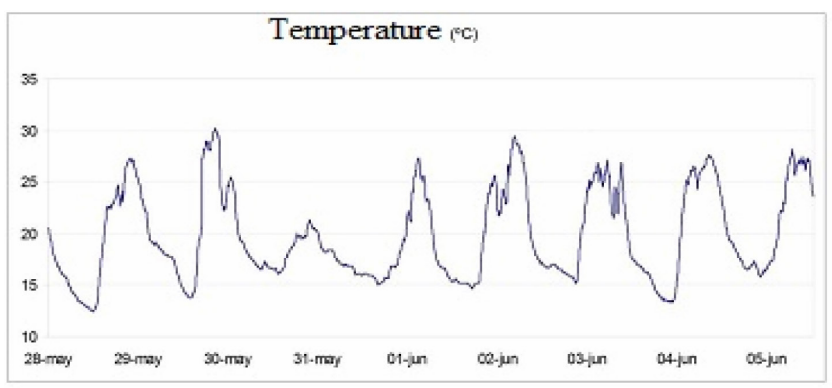

Figure 10. Temperature representation of sensor node.

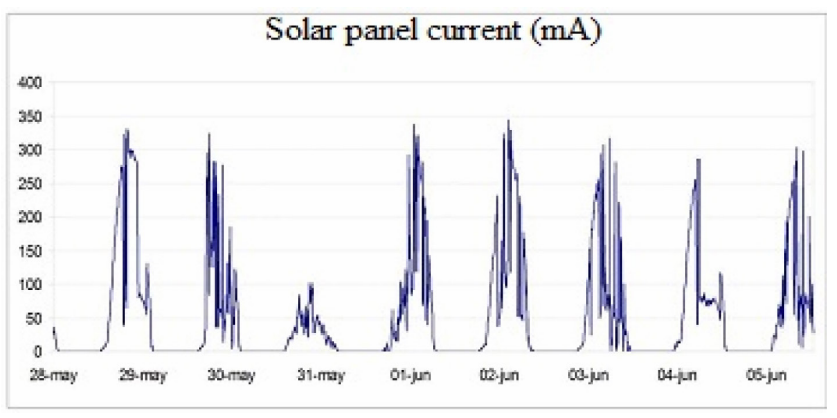

Figure 11. Solar panel current analysis of sensor node. 
inbuilt energy harvesting system. This energy harvesting system is not like a typical power system for nodes, but it is implemented with two rechargeable batteries with automatic battery charging discharging switching system. Thus it provides a high performance energy management system for wireless sensor node for while comparing with single battery energy harvesting system. The replacement time of the battery is increased and the effort need for battery monitoring is decreased. Experimentation result shows the charging and discharging processes and performance of one of the solar powered node using LabVIEW.

\section{References}

1. Prasad RK, Madkar SR. Design \& implementation of wireless transceiver for data acquisition in wireless sensor network. Int J Adv Res Comput Sci Software Eng. 2013 Jul 3(7); 521-526.

2. Patil A, Patil V, Shin DW, Choi J-W, Paik D-S, Yoon S-J. Issue and challenges facing rechargeable thin film lithium batteries. Mater Res Bull. 2008 Aug 4-Sep 4; 43(8-9), 1913-42.
3. Roundy S, Steingart D, Frechette L, Wright P. Power Sources for Wireless Sensor Networks, Australian National University, Department of Engineering, Canberra ACT 0200, Australia.

4. Penella MT. Powering wireless sensor nodes: Primary batteries versus energy harvesting, Instrumentation and Measurement Technology Conference; 2009, I2MTC '09; IEEE.

5. Gani A, Salami, MJE. A LabVIEW based data acquisition system for vibration monitoring and analysis. Student Conference on Research and Development, 2 SCOReD; 2002. p. $62-5$

6. Ososanya ET, Haghani S. The Design of a Wi-Fi Enabled Cloud Monitoring Device. University of the District of Columbia Washington DC; 2008.

7. Bangale K, Gupta N, Parihar SS. Remote data collection server: E-Health care. International Journal of Innovative Research in Computer and Communication Engineering. 2014 Feb; 2(2):2938-42.

8. Siegmund N, Rosenmüller M, Moritz G. Towards robust data storage in wireless sensor networks. IETE Technical Review. 2009 Sep; 26(5). 